\title{
GMR
}

\section{Activation of Src tyrosine kinase in esophageal carcinoma cells in different regulatory environments and corresponding occurrence mechanism}

\author{
Z.S. Yu ${ }^{1}$, X.H. Song ${ }^{2}$, H.M. Gan ${ }^{3}$, D.Z. Geng ${ }^{1}$ and J. Yang ${ }^{1}$ \\ ${ }^{1}$ Department of Oncology, Binzhou Medical University Hospital, Binzhou, \\ Shandong Province, China \\ 2Department of Obstetrics and Gynecology, Binzhou People's Hospital, \\ Binzhou, Shandong Province, China \\ ${ }^{3}$ Intensive Care Unit, Binzhou People's Hospital, Binzhou, \\ Shandong Province, China \\ Corresponding author: D.Z. Geng \\ E-mail: gengdzdo@126.com
}

Genet. Mol. Res. 15 (3): gmr.15038026

Received November 6, 2015

Accepted January 1, 2016

Published August 26, 2016

DOI http://dx.doi.org/10.4238/gmr.15038026

Copyright (C) 2016 The Authors. This is an open-access article distributed under the terms of the Creative Commons Attribution ShareAlike (CC BY-SA) 4.0 License.

\begin{abstract}
This study aims at observing the expression of activated Src tyrosine kinase in esophageal squamous cell carcinoma (ESCC), and exploring the relationship of Src tyrosine kinase with the occurrence and progression of ESCC. Immunohistochemistry, immunofluorescence, and immunoblotting are employed to investigate the expression of Src tyrosine kinase in the ESCC tissue. Cellular immunofluorescence is used to measure the expression of activated $\mathrm{Src}$ tyrosine kinase in TE1 and TE9 cell lines of human ESCC tissues and EPC1-htert and EPC2-htert cell lines of esophageal epithelial cells. Src
\end{abstract}


tyrosine kinase is overexpressed in ESCC tissue and underexpressed in normal esophageal mucosa. Furthermore, it is overexpressed in the TE1 and TE9 cell lines of human ESCC tissue and underexpressed in the EPC1-htert and EPC2-htert cell lines of esophageal epithelial cells. Src tyrosine kinase shows a higher expression in human ESCC tissue than in normal esophageal mucosa. The difference is statistically significant $(\mathrm{P}<0.05)$. The activation of Src tyrosine kinase plays an important role in the occurrence and development of ESCC.

Key words: Esophageal carcinoma; Squamous cell; Src tyrosine kinase; Cell activation

\section{INTRODUCTION}

Tumor malignancy is one of the main factors causing human death, being the number one cause of death in some developed countries, with its morbidity and mortality increasing every year. The incidence of digestive system malignancy accounts for approximately $2 / 3$ of the whole body malignancy. Esophageal carcinoma is one of the most common digestive system malignancies spreading around the world (Chen et al., 2013), with China being a high-incidence area of the type of carcinoma. In China, esophageal carcinoma mortality accounts for $21.8 \%$ of the whole cancer mortality, while in the Henan Province of China, it accounts for about $40 \%$ of the total carcinoma mortality. About 25,000 people on average die of esophageal carcinoma per year in China (Song et al., 2012). Esophageal carcinoma originates from esophageal mucosal epithelial basal cells. In the high-incidence areas in China, its pathological type is mainly manifested as ESCC, which accounts for about $95 \%$ of the cases. Therefore, research on ESCC presents obvious practical significance (Wen et al., 2013).

Src tyrosine kinase belongs to the non-receptor, tyrosine kinase family. The activation of kinase is involved in the signal transduction process related to multiple cell functional activities, such as proliferation, differentiation, movement, migration, and angiogenesis (Sancier et al., 2011; Huang et al., 2012). In fact, Src tyrosine kinase can also interact with many proteins, including platelet-derived growth factor receptor, vascular endothelial growth factor receptor, and human epidermal growth factor receptor (Ischenko et al., 2010). Due to historical reasons, research on the Src Family Kinase Src (SFKS) in carcinoma majorly focused on the fibroblasts of birds and mammals and human hematopoietic cells (Ma et al., 2012). Recently, many studies show that the abnormal overexpression of Src tyrosine kinase is associated with the occurrence of multiple epithelial-originated tumors, i.e., human colon carcinoma, breast carcinoma, and nonsmall cell lung carcinoma (Chellappa et al., 2012; Lv and Tian, 2012).

This study is designed with the following purposes: firstly, to explore the relationship of Src tyrosine kinase and ESCC through different methods; secondly, to observe the interactions of Src tyrosine kinase and ESCC by transfecting related signal molecule plasmid DNA; finally, to reveal possible negative regulatory mechanism and involved molecules of Src tyrosine kinase in ESCC.

Genetics and Molecular Research 15 (3): gmr.15038026 


\section{MATERIAL AND METHODS}

\section{Materials}

The specimens were collected from 20 ESCC operations in our hospital, including ESCC tissue and normal esophageal mucosa tissue adjacent to carcinoma. After resection, part of the specimens were labeled and immediately reserved in the refrigerator at $-20^{\circ} \mathrm{C}$.

Human ESCC TEI cell line was purchased from Huhhot Moer Biotechnology Co., Ltd., China. The human esophageal mucosa epithelial EPCI-hTERT cell line was purchased from Shanghai Boye Biotechnology Co., Ltd., China. DMEM culture medium was purchased from Fermentas Co., Ltd., USA. Human Srcasm plasmid was purchased from Baoman Biotechnology Co., Ltd., China. DAB substrate kit was purchased from Fermentas Co., Ltd., USA. Labeled goat anti-rabbit IgS (IHC) was purchased from Ruiqi Biological Technology Co., Ltd., China. Bovine serum albumin was purchased from Ruiqi Biological Technology Co., Ltd., China. LIP of ectamine reagent was purchased from Sigma Co., Ltd., USA. EL-Einsatz microscope was purchased from Corvallis Co., Ltd., USA. Inverted microscope was purchased from Labnet Co., Ltd., USA.

\section{Immunohistochemical staining}

After being placed in tissue boxes and labeled, carcinoma tissues were immersed in $5 \%$ neutral formalin for fixation for $48 \mathrm{~h}$, and washed with water for $12 \mathrm{~h}$. Afterward, they were dehydrated by gradient ethanol and immersed in dimethylbenzene for transparency treatment. After being embedded in paraffin, they were sectioned. All specimen sections were put on stainless steel slice planes of an oven at $55^{\circ} \mathrm{C}$ for dewaxing for $15 \mathrm{~min}$, and washed in $100 \%$ ethanol solution for $10 \mathrm{~min}$. Then, they were incubated in citrate buffer, $\mathrm{pH} 6.0$, at $85^{\circ} \mathrm{C}$ for $60 \mathrm{~min}$, cooled at room temperature for $30 \mathrm{~min}$, and washed for $10 \mathrm{~min}$ with distilled water. Afterwards, they were placed in $3 \% \mathrm{H}_{2} \mathrm{O}_{2}$ for $10 \mathrm{~min}$ to inactivate endogenous peroxidases and biotin, washed with distilled water for $10 \mathrm{~min}$ and with phosphate-buffered solution (PBS) for $5 \mathrm{~min}$, followed by, finally, an incubation in bovine serum albumin for $1 \mathrm{~h}$ at room temperature.

The sections obtained above were firstly incubated in antibody dilution at $4^{\circ} \mathrm{C}$ overnight and then rewarmed at room temperature for $30 \mathrm{~min}$. After the first antibody dilution was removed, they were washed three times with PBS, 10 min for each time. Secondly, the sections were incubated in affinity purification biotin-marked goat anti-rabbit polyclonal immunoglobulin dilution for $30 \mathrm{~min}$. After the second antibody was removed, they were washed three times with PBS, 10 min for each time. Thirdly, the sections were incubated in horseradish peroxidase solution for $40 \mathrm{~min}$, and then washed three times with PBS, $10 \mathrm{~min}$ for each time. Fourthly, the sections were incubated in $\mathrm{DAB}$ substrate chromogenic reagent kit, and then washed for $10 \mathrm{~min}$ with distilled water. Fifthly, they were re-stained using hematoxylin and washed with flow water. Finally, we dropped a droplet of sealing section liquid on glass slide tissue, then put cover glass on this sealing section liquid from one corner and slowly covered it with cover glass. With the cover glass downward on absorbed paper, the slide was observed on the microscope.

\section{Immunohistochemical staining intensity analysis}

All sections were inspected by two independent pathologists at our hospital, in order to judge the staining intensity and staining range of the ESCC and control groups. The staining

Genetics and Molecular Research 15 (3): gmr.15038026 
intensity grading was as follows: 1) no staining, 2) weak staining, 3) moderate staining, and 4) intensive staining. The staining range classification was: 1) $0-25 \%$, 2) $25-50 \%, 3) 50-75 \%$, and 4) $75-100 \%$. The staining index is the product of staining intensity and staining range, with the maximum staining index being 18 and the minimum being 0 (Richendrfer et al., 2009).

\section{Immunofluorescence observation of tissue section}

Sections were firstly incubated in citrate buffer, $\mathrm{pH} 6.0$, for $20 \mathrm{~min}$ at $85^{\circ} \mathrm{C}$. After being placed at room temperature for $30 \mathrm{~min}$, they were washed with distilled water for $10 \mathrm{~min}$. Then, they were immersed in $3 \% \mathrm{H}_{2} \mathrm{O}_{2}$ for 10 min to inactivate the endogenous peroxidases and biotin, and washed with distilled water and PBS for 10 and 5 min, respectively. After that, they were incubated in sealing liquid for $1 \mathrm{~h}$ at room temperature for sealing non-specific antigens. Then, they were incubated in the antibody dilution at $4^{\circ} \mathrm{C}$ overnight and rewarmed for $30 \mathrm{~min}$. After this antibody dilution was removed, they were washed with PBS and high salt PBS for $10 \mathrm{~min}$ each. Then, they were incubated with the second antibody dilution in cassette for $1 \mathrm{~h}$. After the second antibody dilution was removed, they were washed with PBS and high salt PBS for 10 min each. Finally, they were sealed using ProLong Gold antifade reagent with DAPI sealing liquid, and observed on the microscope.

\section{Cell culture}

The conventional culture method was used for the TE1 and TE9 cell lines. They were cultivated in DMEM culture solution containing $10 \%$ fetal bovine serum at $37^{\circ} \mathrm{C}$ and saturated humidity with $5 \% \mathrm{CO}_{2}$. Culture solution was replenished every 3 days. These cell lines underwent one passage and the cells in the logarithmic growth phase were used as experimental objects.

The EPC1-htert and EPC2-htert cell lines were cultivated in K-SFM medium culture solution comprising $40 \mu \mathrm{g} / \mathrm{mL}$ bovine pituitary extract, $1.0 \mathrm{ng} / \mathrm{mL}$ epidermal growth factor (EGF), and $100 \mathrm{IU} / \mathrm{mL}$ streptomycin, at $37^{\circ} \mathrm{C}$ and saturated humidity with $5 \% \mathrm{CO}_{2}$. The culture solution was replenished every 4 days. These cell lines underwent one passage and the cells in the logarithmic growth phase were used as experimental objects.

\section{Protein expression level by Western blot analysis}

Protein samples stored at $-80^{\circ} \mathrm{C}$ were placed on ice. According to protein concentration, we extracted certain protein samples and mixed these samples with loaded buffer into the same volume. After being oscillated to be even, the solutions obtained were subjected to rapid centrifugation for $15 \mathrm{~s}$ through low-temperature ultracentrifugation. Then, they were drybathed for $10 \mathrm{~min}$ at $100^{\circ} \mathrm{C}$ to fully denature the proteins. After being moved into ice-bath for a 10 -min incubation, they were re-centrifuged rapidly for $15 \mathrm{~s}$. The samples obtained were placed in ice-bath for use. Sample-adding holes were blown by pipettes. Isopyknic standard protein samples were added into these holes. The blank hole was injected with the same volume of just loading buffer. Then, we closed the electrophoresis tank cover and proceeded with 130-V steady electrophoresis until the tracers arrived at the bottom of gel plate. The gels obtained were removed and the lower right corners of the gels were cut to mark direction. Then, these gels were moved to transfer membrane buffer for a mild oscillation of $10 \mathrm{~min}$ (70

Genetics and Molecular Research 15 (3): gmr.15038026 
$\mathrm{rpm})$. Meanwhile, the polyvinylidene difluoride membranes in appropriate sizes were cut and put in methanol for activation for $1 \mathrm{~min}$. Finally, by referring to the operating instructions of the ECL reagent kit, we completed the exposure, fixation, and visualization.

\section{Construction of Srcasm adenovirus vector (Ad-Srcasm)}

The liposome method was employed for the transfection of human pcDNA3.1Srcasm vector into human ESCC TEI cell lines, using a pcDNA3.1 empty vector (Mock) as control. Human ESCC TE1 cell lines were infected by Ad-Srcasm with an infection multiplicity of 100, with the adenovirus containing bacterial LacZ promoter in the green fluorescent protein coding region (Ad-GFP) as control. At the same time, the blank control group was set. The proteins of the cells harvested were extracted using RIPA plus inhibitor cell lysis. The concentrations of the proteins were obtained using the standard curve method and conventional western blot detection.

\section{Transfection of pcDNA3.1-Srcasm plasmid to human ESCC TE1 cell line}

Human ESCC TE1 cell lines were cultured on 6-cm culture dishes using the conventional method, with $60 \%$ contact. They were transfected with different doses $(0,0.125$, $0.25,0.5,1$, and $2 \mu \mathrm{g}$ ) of pcDNA3.1-Srcasm plasmid DNA. The proteins obtained were detected through western blot.

\section{Statistical analysis}

The normality test was conducted in routine. The experimental data are reported as means \pm standard deviation. Single variable between the data of two groups employed the Student $t$-test. $\mathrm{P}<0.05$ was defined as statistical significance. The data were processed using the SPSS 13 statistical software.

\section{RESULTS}

\section{Expression of Src tyrosine kinase in ESCC tissue and normal mucosa tissue by immunohistochemistry}

According to immunohistochemical staining analysis, cells were in dark staining color, close arrangement, and irregular shapes in ESCC tissue, as shown in Figure 1.

\section{Staining intensity of Src tyrosine kinase protein in ESCC tissue and normal mucosa tissue by immunohistochemistry}

The immunohistochemical staining indexes of all sections were analyzed through a semi-quantitative method. The maximum staining index was 25 , and the minimum was zero. The staining indexes of Src tyrosine kinase protein in ESCC tissue (18.62 \pm 4.30$)$ were significantly higher than those in normal mucosa tissue $(7.31 \pm 2.56)$, as shown in Figure $2(\mathrm{P}<0.05)$. 


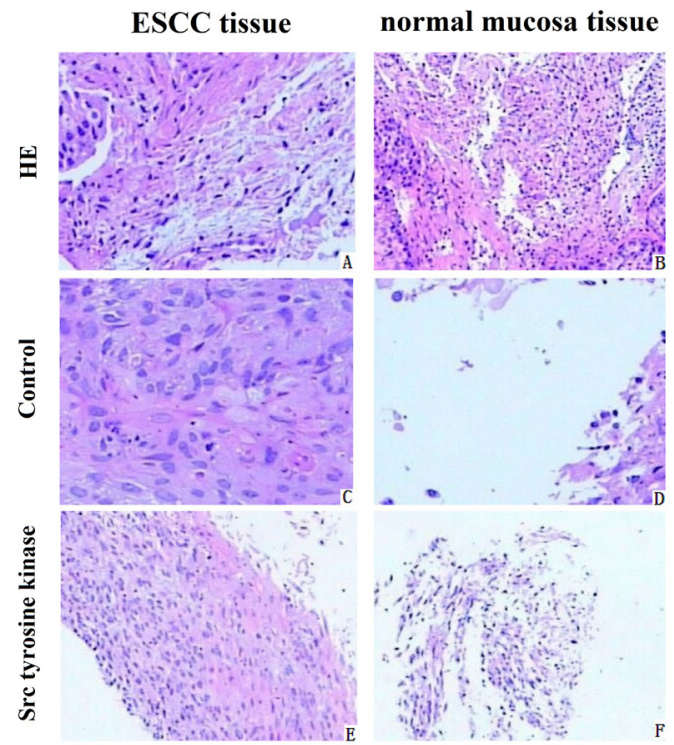

Figure 1. Expression of Src tyrosine kinase in ESCC tissue (left) and normal mucosa tissue (right) through immunohistochemistry. A. and B. H\&E staining of esophageal squamous cell carcinoma and normal tissue; $\mathbf{C}$. and D. first antibody Src tyrosine kinase substituted by purified rabbit IgG; E. and F. esophageal squamous cell carcinoma tissue showing intensive staining.

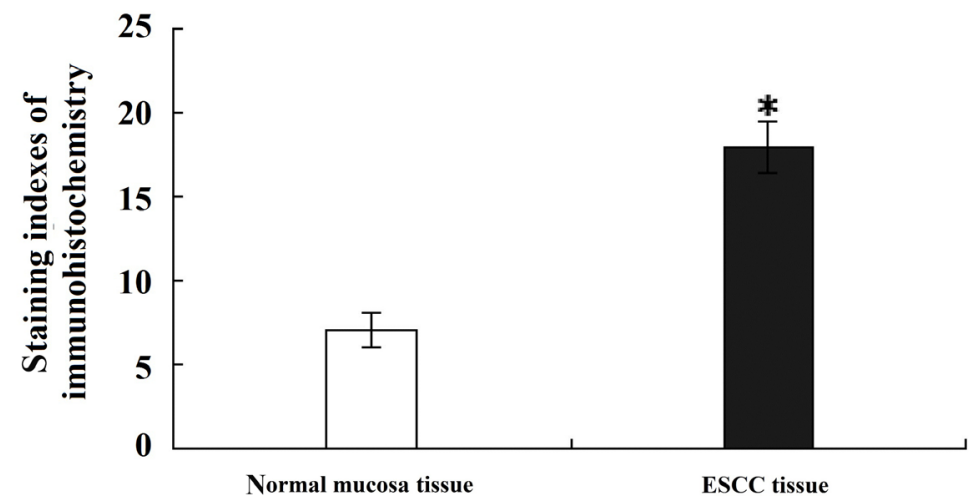

Figure 2. Staining intensity of Src tyrosine kinase protein in esophageal squamous cell carcinoma tissue and normal mucosa tissue through immunohistochemistry. $* \mathrm{P}<0.05$.

\section{Expression of Src tyrosine kinase in ESCC and normal mucosa tissue by immunofluorescence}

The fluorescence intensity of Src tyrosine kinase in ESCC was significantly higher than that in normal mucosa tissue. The nucleus was stained in dark color. After nucleus removal, the fluorescence intensity of the cytoplasm in ESCC was also higher than that in normal mucosa tissue, as shown in Figure 3. 

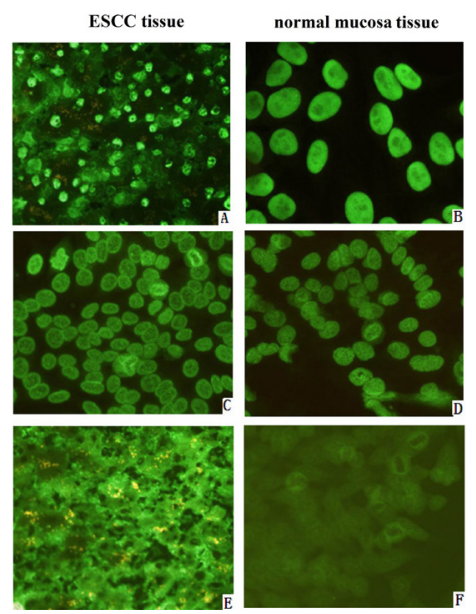

Figure 3. Expressions of Src tyrosine kinase protein in esophageal squamous cell carcinoma (left) and normal mucosa tissue (right) by immunofluorescence. A. and B. nucleus highlighted by DAPI re-staining; C. and D. the second antibody was labeled by Texas red; nucleus highlighted by DAPI re-staining. Observe Src tyrosine kinase protein fluorescence; E. and $\mathbf{F}$. after nucleus removal, observe the fluorescence of cytoplasm.

\section{Expression of Src tyrosine kinase in ESCC and normal mucosa tissues by western immunoblotting}

Through western immunoblotting, it was observed that the expression of Src tyrosine kinase protein in ESCC was statistically higher than that in normal esophageal mucosa (P $<0.05)$. The gray level was measured using the Quantity-one software and through $\beta$-actin standardization. The results showed that the expression of Src tyrosine kinase protein in ESCC was significantly higher than that in control group, as shown in Figure 4.

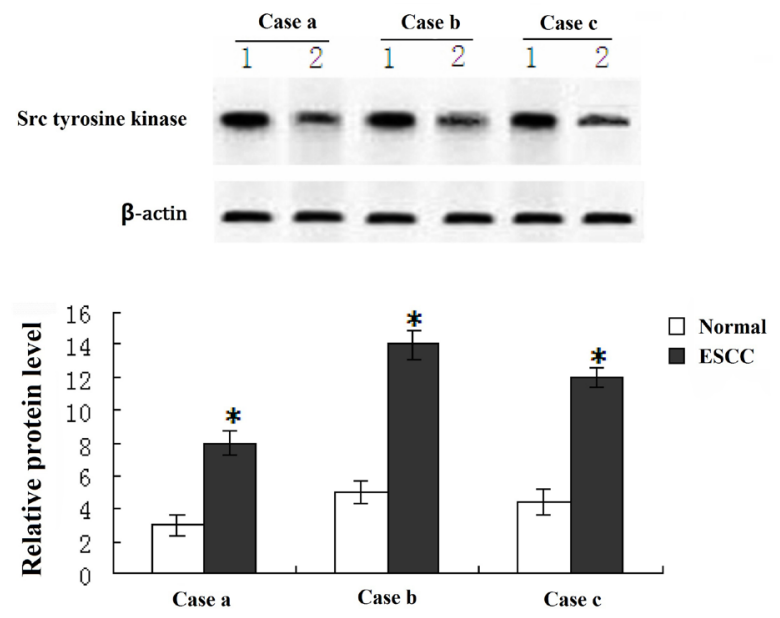

Figure 4. Expression of Src tyrosine kinase in esophageal squamous cell carcinoma and normal mucosa by Western immunoblotting. ${ }^{*} \mathrm{P}<0.05$. 


\section{Expression of Src tyrosine kinase expression in ESCC TE1 cell line and esophageal} epithelial EPC2-htert cell line by immunofluorescence

Texas red was used to label the second antibody and DAPI re-staining was used to highlight the nucleus. The expression of Src tyrosine kinase protein was observed under green fluorescence. The results indicated that the expression of Src tyrosine kinase protein in the ESCC TE1 cell line was higher than that in esophageal epithelial EPC2-htert cell line, as shown in Figure 5.

TE1 cell line

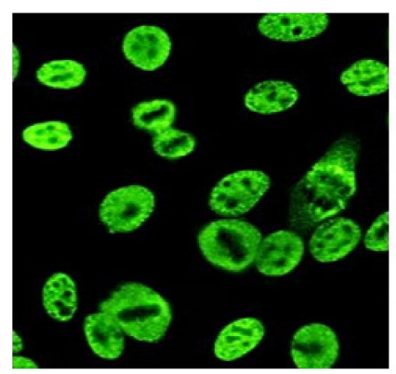

EPC2-htert cell line

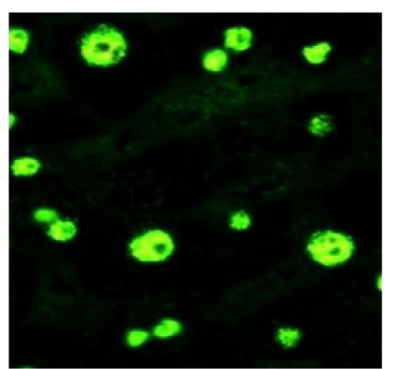

Figure 5. Expression of Src tyrosine kinase in esophageal squamous cell carcinoma TE1 cell line (left) and esophageal epithelial cell EPC2-htert cell line (right) by immunofluorescence.

\section{Expression of Src tyrosine kinase in TE1, TE9, EPC1-htert, and EPC2-htert cell lines by immunoblotting}

Through western immunoblotting, it was found that the expression of Src tyrosine kinase in ESCC TE1 and TE9 cell lines was significantly higher than that in normal esophageal epithelial EPC1-htert and EPC2-htert cell lines $(\mathrm{P}<0.05)$, as shown in Figure 6.

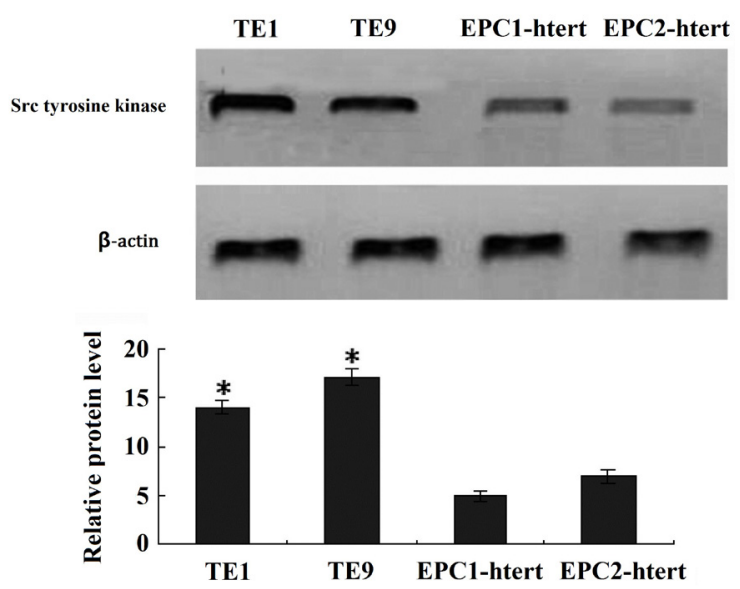

Figure 6. Expression of Src tyrosine kinase in TE1, TE9, EPC1-htert, and EPC2-htert cell lines by immunoblotting. Comparing with normal esophageal epithelial EPC1-htert and EPC2-htert cell lines, $* \mathrm{P}<0.05$. 


\section{Identification of human ESCC cell line TE1 after pcDNA3.1-Srcasm plasmid DNA transfection and Ad-Srcasm adenovirus infection}

The results showed that Srcasm protein expression of the TE1 cell line treated by pcDNA3.1-Srcasm and Ad-Srcasm was significantly increased. This phenomenon suggests that plasmid DNA transfection and adenovirus infection are both feasible. The gray level was measured using the Quantity-one software and through $\beta$-actin standardization. The results showed that the efficiency of pcDNA3.1-Srcasm plasmid DNA transaction was higher than that of Ad-Srcasm adenovirus infection, as shown in Figure 7.
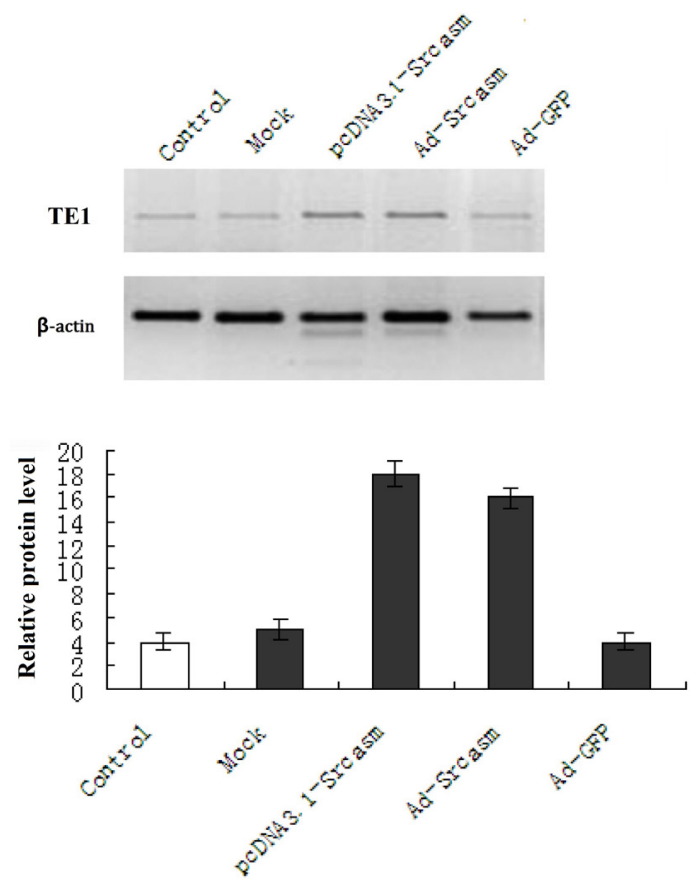

Figure 7. Expression of the Srcasm protein treated by Srcasm plasmid DNA and adenovirus vector.

\section{Dose-dependent experiment of human ESCC cell line TE1 transfection by pcDNA3.1-Srcasm plasmid DNA}

The experimental results showed that the expression of Srcasm protein in TE1 cells increasead gradually with the growing of the transfection dose of pcDNA3.1-Srcasm plasmid DNA. This phenomenon demonstrated that transfection was favorable. Meanwhile, the expression of activated Src tyrosine kinase reduced gradually. The gray level was measured using the Quantity-one software and through $\beta$-actin standardization. The results indicated that with the increase of the transfection dose of pcDNA3.1-Srcasm plasmid DNA to the TE1 cell line, the expression of Srcasm showed a negative correlation with Src tyrosine kinase protein expression. We propose that Srcasm may play a negative regulatory role on the activated Src tyrosine kinase, as shown in Figure 8. 

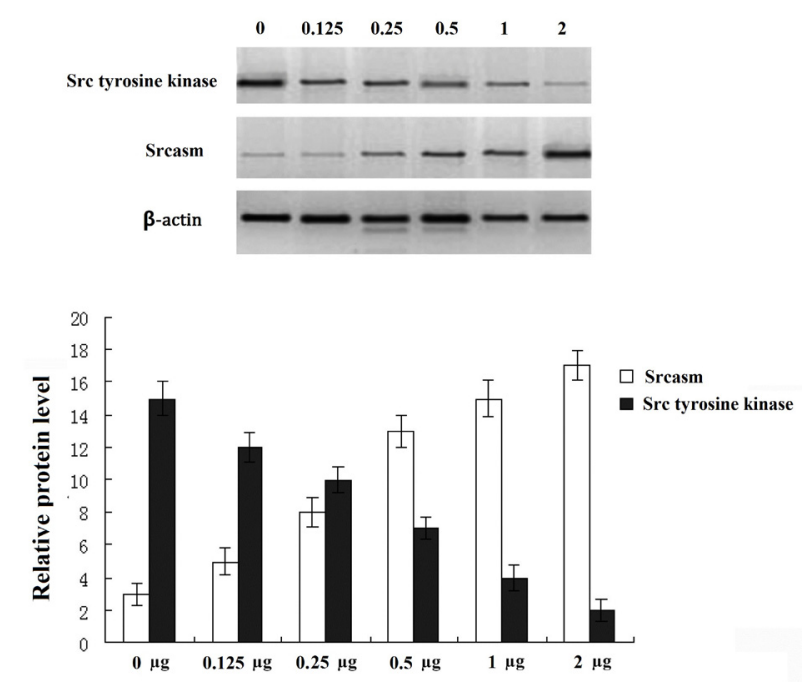

Figure 8. Dose-dependent experiment of human ESCC cell line TE1 transfection by pcDNA3.1-Srcasm plasmid DNA.

\section{DISCUSSION}

Esophageal carcinoma is a common digestive tract malignancy. More than 200 thousand people die of esophageal carcinoma around the world each year, with China being one of the high-incidence areas of this type of carcinoma. Esophageal carcinoma ranks second, after gastric carcinoma, in terms of mortality. In the high-incidence areas of esophageal carcinoma in China, the pathological pattern of esophageal carcinoma is mainly concentrated on ESCC, which accounts for about 95\% of the cases (Wang et al., 2012). Previous studies suggested that the occurrence of esophageal carcinoma was related to nitrosamine compounds, trace elements deficiency, and genetic susceptibility. However, they did not determine the definite pathogenesis of esophageal carcinoma. This situation is one of the key reasons that still lead to unsatisfactory treatment effects (Chattopadhyay et al., 2009). The esophageal mucosa surface is covered with stratified squamous epithelium, with the normal esophageal mucosa epithelium being able to proceed self-renewing to maintain epithelial cell growth and terminate differentiation (Lu et al., 2010; Pink et al., 2011). Controlling how esophageal epithelium transfers from differentiation to proliferation is one of the approaches to cure esophageal epithelium diseases. This approach is especially significant to the pathogenesis study of esophageal carcinomas (Chen et al., 2011).

The Src tyrosine kinase family comprises at least 9 kinds of non-receptor tyrosine kinases with highly similar structures, which are Src, Fyn, Yes, Lck, Hck, Lyn, Blk, Yrk, and Fgr. Src tyrosine kinase is constituted by the N-myristoylation sequence, single sequence, $\mathrm{SH} 2$ structural domain, SH3 structural domain, kinase domain, and C-regulatory domain (Takadera et al., 2012). Through the N-myristoylation radical, Src tyrosine kinase is anchored on the inside of plasma membrane. The SH2 structural domain consists of about 100-amino acid residues that are used in specific recognition and bind to a short peptide containing phosphotyrosine. The SH3 structural domain comprises about 50-amino acid residues, which can combine with the target protein through proline and hydrophobic amino acid residues. The kinase domain contains the positive regulatory autophosphorylation site Y416 and the C-regulatory domain 
contains the negative regulatory autophosphorylation site Y527 (Wortmann et al., 2011). The SH3 domain is also crucial for cytoskeleton recombination and Src protein translocation, while the SH2 and kinase domains are important in signal transduction (Mittal et al., 2011). In normal cells, Y527 is prone to be phosphorylated due to the presence of the Src kinase (CSK) at the carboxyl terminal. Then, the combination of phosphorylated Y527 and SH2 domain leaves the SFKs protein in an inhibitory state with a curling head and tail. However, as for the cells that have developed into cancer or in the mitotic phase, the SFK protein is placed in open conformation due to the Y527 phosphorylation decomposition and Y416 selfphosphorylation. Thus, they can be activated (Yu et al., 2011; Bai et al., 2012).

Once it is activated, Src tyrosine kinase can participated in multiple-functional activities in vivo, including proliferation, differentiation, cell movement, migration, and angiogenesis. However, the carcinogenicity of the overexpression of wild Src is very weak (Campone et al., 2012). In addition, some studies have shown that the Src kinase activation caused by mutation is rare in a variety of human tumors (Zheng et al., 2011). In short, due to the variation potential limitation and the activity mutation deficiency of Src kinase in human tumors, further studies on the effects of Src tyrosine kinase to the occurrence and progression of tumors have been hindered for a long time. Recently, some studies have reported that the overexpression of wild Src can promote the activity of other signaling pathway molecules (Elsberger et al., 2010; Yasmeen et al., 2010). In fact, Src kinase has been proven to be able to react with a variety of proteins, including receptor tyrosine kinase-colony-stimulating factor receptor-1, plateletderived growth factor receptor, vascular endothelial growth factor receptor, human epidermal growth factor receptor-2, and human epidermal growth factor receptor-3 (Ferrando et al., 2012; Nagaraj et al., 2013). Other acting factors include signal transduction and transcription activation factors, heterotrimeric G protein, mitogen-activated protein kinase (MAPK), cyclin $\mathrm{D}$ and $\mathrm{E}$, and focal adhesion kinase (Khoury et al., 2009). In antigen-presenting cells, the tyrosine kinase Fyn in Src family has a gathering effect that can be activated by the proteins of lymphocyte activation molecule family through its SH3 structural domain (Sarkar et al., 2012). Recently, a number of studies have shown that the activation of Src tyrosine kinase is associated with the occurrence and progression of multiple-human malignancies (Basu et al., 2009). Ueda et al. (2009) indicated that activated Src tyrosine kinase was related to the occurrence of colon carcinoma. Especially for patients that had developing colon carcinoma metastasis, the expression level of Src tyrosine kinase was higher (Ueda et al., 2009). Through ELISA, Zhao and Planas-Silva (2009) confirmed that the activated Src tyrosine kinase level in colon carcinoma tissues was twice higher than that in normal mucosa tissue adjacent to carcinoma. Moreover, it was positively related to the stage of the colon carcinoma (Zhao and Planas-Silva, 2009). The present study detected the activated Src tyrosine kinase level in 30 cases of ESCC and 30 cases of normal esophageal mucosa using immunohistochemistry and immunofluorescence. The results showed that the expression of Src tyrosine kinase protein in ESCC was significantly higher than that in control group. Simultaneously, we measured the expression of Src tyrosine kinase in ESCC TE1 and TE9 cell lines with human esophageal mucosa epithelial EPC1-Htert and EPC2-htert cell lines as control group and obtained similar results. It was prompted that the activation of Src tyrosine kinase is a common phenomenon of ESCC and was involved in the signal transduction formed by ESCC.

However, it is perceived that the activity mutation of Src tyrosine kinase is rare in many human tumor tissues. Therefore, the impairment of the negative regulatory mechanism of Src tyrosine kinase may be the main reason inducing the expression level increase of Src

Genetics and Molecular Research 15 (3): gmr.15038026 
tyrosine kinase in these human tumors (Oh et al., 2008). Unfortunately, this study merely takes human ESCC cell lines as research objects to prove that Src tyrosine kinase may participate in different expressions regulating ESCC. Furthermore, in vivo experiments are still lacking. Thus, further studies are required to further prove the results obtained and deeply recognize the corresponding mechanism.

\section{Conflicts of interest}

The authors declare no conflict of interest.

\section{ACKNOWLEDGMENTS}

Research supported by the Technology Reserve Project of Provincial Department of Science and Technology, Binzhou Medical University Hospital.

\section{REFERENCES}

Bai L, Yang JC, Ok JH, Mack PC, et al. (2012). Simultaneous targeting of Src kinase and receptor tyrosine kinase results in synergistic inhibition of renal cell carcinoma proliferation and migration. Int. J. Cancer 130: 2693-2702. http:// dx.doi.org/10.1002/ijc. 26303

Basu N, Bhandari R, Natarajan VT and Visweswariah SS (2009). Cross talk between receptor guanylyl cyclase C and c-src tyrosine kinase regulates colon cancer cell cytostasis. Mol. Cell. Biol. 29: 5277-5289. http://dx.doi.org/10.1128/ $\underline{\mathrm{MCB} .00001-09}$

Campone M, Bondarenko I, Brincat S, Hotko Y, et al. (2012). Phase II study of single-agent bosutinib, a Src/Abl tyrosine kinase inhibitor, in patients with locally advanced or metastatic breast cancer pretreated with chemotherapy. Ann. Oncol. 23: 610-617. http://dx.doi.org/10.1093/annonc/mdr261

Chattopadhyay I, Phukan R, Singh A, Vasudevan M, et al. (2009). Molecular profiling to identify molecular mechanism in esophageal cancer with familial clustering. Oncol. Rep. 21: 1135-1146.

Chellappa K, Jankova L, Schnabl JM, Pan S, et al. (2012). Src tyrosine kinase phosphorylation of nuclear receptor HNF4a correlates with isoform-specific loss of HNF4a in human colon cancer. Proc. Natl. Acad. Sci. USA 109: $2302-2307$. http://dx.doi.org/10.1073/pnas.1106799109

Chen X, Zhao P, Chen F, Li L, et al. (2011). Effect and mechanism of 5-aminolevulinic acid-mediated photodynamic therapy in esophageal cancer. Lasers Med. Sci. 26: 69-78. http://dx.doi.org/10.1007/s10103-010-0810-0

Chen W, He Y, Zheng R, Zhang S, et al. (2013). Esophageal cancer incidence and mortality in China, 2009. J. Thorac. Dis. 5: 19-26.

Elsberger B, Tan BA, Mallon EA, Brunton VG, et al. (2010). Is there an association with phosphorylation and dephosphorylation of Src kinase at tyrosine 530 and breast cancer patient disease-specific survival. Br. J. Cancer 103: 1831-1834. http://dx.doi.org/10.1038/sj.bjc.6605913

Ferrando IM, Chaerkady R, Zhong J, Molina H, et al. (2012). Identification of targets of c-Src tyrosine kinase by chemical complementation and phosphoproteomics. Mol. Cell. Proteomics 11: 355-369. http://dx.doi.org/10.1074/mcp. $\underline{M 111.015750}$

Huang W, Liu Y, Li L, Zhang R, et al. (2012). HMGB1 increases permeability of the endothelial cell monolayer via RAGE and Src family tyrosine kinase pathways. Inflammation 35: 350-362. http://dx.doi.org/10.1007/s10753-011-9325-5

Ischenko I, Seeliger H, Camaj P, Kleespies A, et al. (2010). Src tyrosine kinase inhibition suppresses lymphangiogenesis in vitro and in vivo. Curr. Cancer Drug Targets 10: 546-553. http://dx.doi.org/10.2174/156800910791517181

Khoury T, Arshad A, Bogner P, Ramnath N, et al. (2009). Apoptosis-related (survivin, Bcl-2), tumor suppressor gene (p53), proliferation (Ki-67), and non-receptor tyrosine kinase (Src) markers expression and correlation with clinicopathologic variables in 60 thymic neoplasms. Chest 136: 220-228. http://dx.doi.org/10.1378/chest.08-2482

Lu TY, Li WB, Wu XA, Wang LX, et al. (2010). [Mechanism of apoptosis of esophageal cancer EC9706 in nude mice induced by all-trans retinoic acid]. Zhonghua Zhong Liu Za Zhi 32: 892-896.

Lv J and Tian Y (2012). [Effect of Src tyrosine kinase inhibition on the drug-resistance as well as MDR1 and LRP expression of the human cis-platinum-resistant lung cancer cell line A549/DDP]. Zhongguo Fei Ai Za Zhi 15: 501-506.

Genetics and Molecular Research 15 (3): gmr.15038026 
Ma YC, Shi C, Zhang YN, Wang LG, et al. (2012). The tyrosine kinase c-Src directly mediates growth factor-induced Notch-1 and Furin interaction and Notch-1 activation in pancreatic cancer cells. PLoS One 7: e33414. http://dx.doi. org/10.1371/journal.pone.0033414

Mittal Y, Pavlova Y, Garcia-Marcos M and Ghosh P (2011). Src homology domain 2-containing protein-tyrosine phosphatase-1 (SHP-1) binds and dephosphorylates G(alpha)-interacting, vesicle-associated protein (GIV)/Girdin and attenuates the GIV-phosphatidylinositol 3-kinase (PI3K)-Akt signaling pathway. J. Biol. Chem. 286: 3240432415. http://dx.doi.org/10.1074/jbc.M111.275685

Nagaraj C, Tang B, Bálint Z, Wygrecka M, et al. (2013). Src tyrosine kinase is crucial for potassium channel function in human pulmonary arteries. Eur. Respir. J. 41: 85-95. http://dx.doi.org/10.1183/09031936.00211811

Oh AS, Lahusen JT, Chien CD, Fereshteh MP, et al. (2008). Tyrosine phosphorylation of the nuclear receptor coactivator AIB1/SRC-3 is enhanced by Abl kinase and is required for its activity in cancer cells. Mol. Cell. Biol. 28: 6580-6593. http://dx.doi.org/10.1128/MCB.00118-08

Pink RC, Bailey TA, Iputo JE, Sammon AM, et al. (2011). Molecular basis for maize as a risk factor for esophageal cancer in a South African population via a prostaglandin E2 positive feedback mechanism. Nutr. Cancer 63: 714-721. http:// dx.doi.org/10.1080/01635581.2011.570893

Richendrfer HA, Wetzel JA and Swann JM (2009). Temperature, peroxide concentration, and immunohistochemical staining method affects staining intensity, distribution, and background. Appl. Immunohistochem. Mol. Morphol. 17: 543-546.http://dx.doi.org/10.1097/PAI.0b013e3181a91595

Sancier F, Dumont A, Sirvent A, Paquay de Plater L, et al. (2011). Specific oncogenic activity of the Src-family tyrosine kinase c-Yes in colon carcinoma cells. PLoS One 6: e17237.http://dx.doi.org/10.1371/journal.pone.0017237

Sarkar TR, Sharan S, Wang J, Pawar SA, et al. (2012). Identification of a Src tyrosine kinase/SIAH2 E3 ubiquitin ligase pathway that regulates C/EBPd expression and contributes to transformation of breast tumor cells. Mol. Cell. Biol. 32: 320-332. http://dx.doi.org/10.1128/MCB.05790-11

Song QK, Li J, Jiang HD, He YM, et al. (2012). Esophageal cancer mortality during 2004-2009 in Yanting County, China. Asian Pac. J. Cancer Prev. 13: 5003-5006. http://dx.doi.org/10.7314/APJCP.2012.13.10.5003

Takadera T, Fujibayashi M, Koriyama Y and Kato S (2012). Apoptosis induced by SRC-family tyrosine kinase inhibitors in cultured rat cortical cells. Neurotox. Res. 21: 309-316. http://dx.doi.org/10.1007/s12640-011-9284-5

Ueda Y, Igishi T, Hashimoto K, Suyama H, et al. (2009). Synergistic cell growth inhibition by the combination of amrubicin and Akt-suppressing tyrosine kinase inhibitors in small cell lung cancer cells: implication of c-Src and its inhibitor. Int. J. Oncol. 34: 689-696.

Wang JB, Fan JH, Liang H, Li J, et al. (2012). Attributable causes of esophageal cancer incidence and mortality in China. PLoS One 7: e42281.http://dx.doi.org/10.1371/journal.pone.0042281

Wen DG, Yang Y, Wen XD and Shan BE (2013). Despite shared susceptibility loci, esophageal squamous cell carcinoma embraces more familial cancer than gastric cardia adenocarcinoma in the Taihang Mountains high-risk region of northern central China. Chin. Med. J. (Beijing, China, Engl. Ed.) 126: 55-60.

Wortmann A, He Y, Christensen ME, Linn M, et al. (2011). Cellular settings mediating Src Substrate switching between focal adhesion kinase tyrosine 861 and CUB-domain-containing protein 1 (CDCP1) tyrosine 734. J. Biol. Chem. 286: 42303-42315.http://dx.doi.org/10.1074/jbc.M111.227462

Yasmeen A, Alachkar A, Dekhil H, Gambacorti-Passerini C, et al. (2010). Locking Src/Abl Tyrosine Kinase Activities Regulate Cell Differentiation and Invasion of Human Cervical Cancer Cells Expressing E6/E7 Oncoproteins of HighRisk HPV. J. Oncol. 2010: 530130. http://dx.doi.org/10.1155/2010/530130

Yu X, Chen M, Zhang S, Yu ZH, et al. (2011). Substrate specificity of lymphoid-specific tyrosine phosphatase (Lyp) and identification of Src kinase-associated protein of $55 \mathrm{kDa}$ homolog (SKAP-HOM) as a Lyp substrate. J. Biol. Chem. 286: 30526-30534.http://dx.doi.org/10.1074/jbc.M111.254722

Zhao Y and Planas-Silva MD (2009). Mislocalization of cell-cell adhesion complexes in tamoxifen-resistant breast cancer cells with elevated c-Src tyrosine kinase activity. Cancer Lett. 275: 204-212. http://dx.doi.org/10.1016/j. canlet.2008.10.022

Zheng R, Qin X, Li W and Kang J (2011). [Effect of Src tyrosine kinase inhibition on secretion of MMP-2 and MMP-9 by non-small cell lung cancer cells]. Zhongguo Fei Ai Za Zhi 14: 13-17.

Genetics and Molecular Research 15 (3): gmr.15038026 